\title{
FUNDAMENTAL SPUTTERING STUDIES: \\ NONRESONANT IONIZATION OF SPUTTERED NEUTRALS ${ }^{\dagger}$
}

\author{
J.W. Burnett, ${ }^{*}$ M.J. Pellin, W.F. Calaway, D.M. Gruen, \\ Materials Science and Chemistry Divisions \\ Argonne National Laboratory \\ Argonne, IL 60439 \\ and \\ J.T. Yates, Jr. \\ Department of Chemistry \\ Surface Science Center \\ University of Pittsburgh \\ Pittsburgh, PA 15260
}

ANL/ PP- -65910

†Work supported by the U.S. Department of Energy, BES-Materials Sciences, under Contract W-31-109-ENG-38

* Department of Chemistry, Surface Science Center, University of Pittsburgh, Pittsburgh, PA 15260

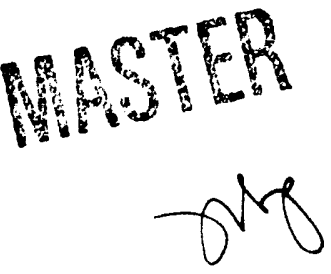




\begin{abstract}
Because of the practical importance of sputtering, numerous theories and computer simulations are used for predicting many aspects of the sputtering process. Unfortunately, many of the calculated sputtering results are untested by experiment. Until recently, most sputtering experiments required either very high ion fluences or the detection of only minor constituents of the sputtered flux, i.e., ions. These techniques may miss the subtleties involved in the sputtering process. High-detection-efficiency mass spectrometry, coupled with the laser ionization of neutral atoms, allows the detection of the major sputtered species with very low incident ion fluences.
\end{abstract}

The depth-of-origin of sputtered atoms is one example of an important but poorly understood aspect of the sputtering process. Ey following the sputtering yield of a substrate atom with various coverages of an adsorbed overlayer, the depth of origin of sputtered atoms has been determined. Our results indicate that two-thirds of the sputtered flux originates in the topmost atomic layer.

The ion-dose dependence of sputtering yields has long been assumed to be quite minor for low-to-moderate primary ion fluences. We have observed a two-fold decrease in the sputtering yield of the Ru(0001) surface for very low primary ion fluences. Data analysis results in a cross section for damage of $2.7 \pm 1.0 \times 10^{-15} \mathrm{~cm}^{2}$.

KEYWORDS: Sputtering, Secondary Neutral Mass Spectrometry (SNMS), ion damage, sputtering yield

\title{
DISCLAIMER
}

This report was prepared as an account of work sponsored by an agency of the United States Government. Neither the United States Government nor any agency thereof, nor any of their employees, makes any warranty, express or implied, or assumes any legal liability or responsibility for the accuracy, completeness, or usefulness of any information, apparatus, product, or process disclosed, or represents that its use would not infringe privately owned rights. Reference herein to any specific commercial product, process, or service by trade name, trademark, manufacturer, or otherwise does not necessarily constitute or imply its endorsement, recommendation, or favoring by the United States Government or any agency thereof. The views and opinions of authors expressed herein do not necessarily state or reflect those of the United States Government or any agency thereof. 


\section{Introduction}

Since its discovery, the sputtering process has been the object of considerable scientific interest. Techniques, using an ion beam as a surface probe, rank among the most quantitative and sensitive analytical surface techniques available. Secondary Ion Mass Spectrometry (SIMS) and Secondary Neutral Mass Spectrometry (SNMS) are two such techniques. Sputtering is also used for the removal of target material in a controlled manner. The coupling of ion milling with SIMS, SNMS, or Auger spectroscopy has proven to be a powerful method of measuring concentration depth profiles. Thin films and, more recently, specialized alloys are grown using sputtering as a method of deposition. Sputtering is also sometimes an undesirable phenomenon. Damage of materials in plasma environments, such as fusion devices, can be the result of sputtering.

Because of the technological importance of the sputtering process, numerous models and theories have been developed to predict many aspects of sputtering. Behavior of the sputtered species, such as the sputtering yield, angular distributions, and energy distributions, are a few of the calculated predictions of these models. The dynamic changes occurring in the target leading to ejection, the "collision cascade," as well as the final target atomic positions, are also determined by model calculations. Many of the results of the models are untested by experiment. In order to more effectively utilize the sputtering process as a scientific tool and also to minimize unwanted damage associated with sputtering, it is important to increase our understanding of the sputtering process.

Until recently, most experiments involving the examination of the sputtering process required the removal of large quantities of target material. Angular distributions and sputtering yields were 
determined by the collection of sputtered material on a substrate followed by analysis. ${ }^{1}$ Detection of secondary ions, as in SIMS, monitors only a minor constituent of the sputtered species. ${ }^{2}$ Furthermore, the sputtered ion fraction is strongly dependent upon the composition of the target material. ${ }^{2,3}$ Therefore, the use of these techniques can mask the subtleties involved in sputtering.

Nonresonant laser ionization of sputtered species monitors the sputtered neutral flux. The neutral fraction of the sputtered flux is the major sputtered component from most target materials. ${ }^{1-3}$ Furthermore, the neutral fraction suffers significantly less severe matrix effects than does the ion fraction. ${ }^{1-3}$ Highdetection-efficiency mass spectrometry, coupled with laser ionization of sputtered neutrals, allows the detection of the major sputtered species with very low fluences. ${ }^{4-9}$

We have used nonresonant laser ionization of sputtered atoms to address two important aspects of the sputtering process. Using an independently verifiable monolayer film of $\mathrm{Cu}$ on $\mathrm{Ru}(0001)$, we have measured the depth of origin of sputtered species. Using the pure $\mathrm{Ru}(0001)$ surface, the dependence of sputtering yield on ion dose has been determined for very low primary ion fluences. While the experiments presented here are very different in purpose, they illustrate the powerful capabilities of using nonresonant laser ionization for the detection of sputtered atoms. This technique uniquely allows the quantitative detection of the majority sputtered species with minimal damage to the target surface.

\section{The Depth of origin of Sputtered Atoms}

The depth of origin of sputtered atoms has, until recently, been a controversial topic. A summary of various experimental and theoretical estimates of the sputtering depth of origin are shown in Table I. Analytical sputtering theory, ${ }^{10-14}$ based on an isotropic 
binary collision approximation, is used to define a "characteristic depth of origin," the average depth from which sputtered atoms are ejected. This value ${ }^{10-12}$ was originally estimated to be $\approx 5 \AA$, roughly 2 atomic layers but has recently been reevaluated, resulting in a more shallow estimate of the depth-of-origin. 13,14 Modifications to the model have resulted in a new estimate of $\approx 2.5 \AA$ and have addressed two shortcomings of the early theory. The first is that the analytical calculations originally ignored the angular deflection of low-energy recoils. The second is that the approximation used for the Born-Mayer cross section is inaccurate at lowinteraction energies. ${ }^{13,14}$

Computer simulations, ${ }^{15-20}$ on the other hand, consistently reveal that greater than $75 \%$ of the sputtered atoms emerge from the topmost layer. A recent round robin of computer simulations has been carried out to calculate the ejection probabilities of target atoms with particular energies and positions within the substrate. ${ }^{13}$ The results showed quite remarkable agreement despite the significant differences between the codes in terms of the potentials used and the target morphology models.

While the discrepancy between the analytical theory and computer simulation estimates of the depth of origin no longer exists, Table I illustrates the lack of experimental data. The only experiment explicitly designed to measure the depth of origin of sputtered atoms is the elegant work of Dumke and Tombrello, ${ }^{21}$ which has been repeated recently by Hubbard et al. ${ }^{22}$ Atoms sputtered from a liquid eutectic In-Ga alloy were collected on graphite foils and then examined by RBS. ISS and AES showed that the surface concentration of In $(\approx 94 \%)$ was nearly six times that of the bulk (16.5\%) due to surface segregation. Their results indicated that $85-97 \%$ of the sputtered atoms originate in the first layer. It must be noted, however, that these results are strongly dependent upon the In concentrations in the first and second 
layers. An underestimate of the second layer In concentration would lead to an artificially shallow depth of origin.

In this publication, nonresonant laser ionization of sputtered neutrals is used to investigate the depth of origin of sputtering from solid surfaces. The method of investigation is straight forward. First, a well-characterized $\mathrm{Cu}$ overlayer is deposited upon a clean single-crystal Ru(0001) surface. The sputtering yields of both Ru and $\mathrm{Cu}, \mathrm{Y}_{\mathrm{Ru}}$ and $\mathrm{Y}_{\mathrm{Cu}}$, are simultaneously measured. By quantitatively detecting both $\mathrm{Y}_{\mathrm{Ru}}$ and $\mathrm{Y}_{\mathrm{Cu}}$ as a function of $\mathrm{Cu}$ coverage, the suppression of the $\mathrm{Ru}$ yield and the ratio of the $\mathrm{Cu}$ to $\mathrm{Ru}$ sputtering yield can be determined.

\section{The Ion Dose Dependence of the Sputtering Yield of Ru(0001)}

Sputtering yields have long been considerea to be relatively independent of primary ion dose, particularly for low-to-moderate fluences. Thus, standard sputtering theories ${ }^{10-14}$ and computer simulations ${ }^{15-20}$ of sputtering, as well as experimentally determined sputtering yields of elemental metals, have up to now treated this quantity as a constant for a given primary ion species, energy, and angle of incidence. Historically, sputtering yield measurements have required the removal of significant amounts of material by ion erosion. ${ }^{1}$ These sputtering yield determinations usually utilize either weight loss measurements or the collection of sputtered material for subsequent analysis. A major criteria used in assessing the quality of a sputtering simulation or theory is its ability to correctly predict sputtering yields. However, these calculations are normally performed using perfect, undamaged surfaces.

Using laser ionization of sputtered neutrals and efficiently collecting the resultant photoions, sputtering yields may be measured in real time with fluences of less than 1012 ions $/ \mathrm{cm}^{2}$. In 
the experiment presented here, we have determined the sputtering yield of $\mathrm{Ru}(0001)$ as a function of primary ion dose.

\section{EXPERIMENTAL}

Laser-based ionization of sputtered atoms is simply a specific method of performing SNMS. In these experiments, sputtered neutrals were detected mass spectrometrically following nonresonant laser ionization. The experimental apparatus has been previously described in detail (see Refs. 23,24). A $3.6 \mathrm{keV}, 10-20 \mathrm{nA}$ $\mathrm{Ar}^{+}$beam strikes the target perpendicular to the surface and is used for both ion dosing and actual sputtering yield measurements. During sputtering yield data acquisition, the primary beam was chopped into 500 ns pulses. The sputtered neutral atoms were nonresonantly ionized using the output from a $\mathrm{XeCl}$ excimer laser (308 $\mathrm{nm}$ ) and an energy and angular refocusing time-of-flight (EARTOF) mass spectrometer was used to discriminate masses.

The high-detection sensitivity of this technique allowed sputtering yield data to be obtained under static mode sputtering conditions, using less than $3 \times 10^{11}$ primary ions $/ \mathrm{cm}^{2}$ per data point. This corresponds to less than one ion impact for every 5300 surface atoms, a fluence low enough to assure that ion beam damage does not influence the measurements. To be completely sure, the SNMS signal was monitored for much lower primary ion fluences, $<10^{10}$ primary ions $/ \mathrm{cm}^{2}$. No difference in signal levels was observable for these low fluences in either the depth of origin or the ion dose dependence sputtering yield experiments.

Because $>90 \%$ of the sputtered flux from clean metal surfaces are neutral atoms, measurements of neutral yields are representative of the total sputtered flux. ${ }^{1,2,7}$ The coupling of a large ionizing laser volume relative to the ion spot size results in a solid collection angle of $>1.57 \mathrm{sr}$; therefore, the results presented 
here are believed to be independent of changes in the angular distribution of the sputtered atoms. We have used a relatively long ion pulse to assure that a significant fraction of the sputtered atom energy distribution intersects the laser volume. By changing the time that the laser fires relative to the time that the primary ion pulse strikes the target, we were able to measure signal levels for the entire sputtered atom energy distribution. The results for both the depth of origin and ion dose dependence of the sputtering yield experiments were observed to be independent of the sputtered atom energy distribution.

The Ru single crystal (Metal Crystals and Oxides, Ltd.) was cut and oriented along the (0001) axis to within $\pm 1^{\circ}$ and polished to a mirror finish. A commercially available heater button (SpectraMat Corp.) was used to heat the sample to temperatures of up to $1500 \mathrm{~K}$ for the early sputtering depth-of-origin studies. ${ }^{4,5}$ The crystal was heated by electron beam bombardment for most of the depth of origin and ion dose dependence sputtering yield experiments. A chromel-alumel thermocouple was press-fitted into the crystal for temperature measurements.

Auger spectroscopy was performed using a single pass cylindrical mirror analyzer (PHI Model 11-500A) to monitor the cleanliness of the Ru surface. Cleaning was achieved by repeated cycles of heating the crystal to $1460 \mathrm{~K}$ in a $9.3 \times 10^{-3} \mathrm{~Pa}$ oxygen background and then heating the crystal to $1560 \mathrm{~K}$ in vacuum. ${ }^{25-31}$ Because of the overlap between the carbon and Ru Auger features near $270 \mathrm{eV}$, carbon contamination is difficult to quantify. Other workers ${ }^{25-31}$ have assumed that ratio of the negative-to-positive differentiated Ru Auger signal levels is minimized for a carbon-free surface and has a value of 1.20. Examination of a heavily carboncontaminated Ru(0001) surface revealed that SNMS RuC signal levels are correlated with the carbon concentration. ${ }^{6}$ We have found the RuC signal obtained with SNMS to be a much more 
sensitive indicator of carbon contamination than is the $(-/+)$ Auger ratio method. In these experiments, the surface carbon concentration was always $<5$ at. $\%$ as determined by SNMS. Auger and SNMS analyses ascertained that no other surface contaminants were present.

Following heavy ion bombardment of the Ru crystal and of a polycrystalline Mo target using Auger, SIMS, and SNMS, it was ascertained that no contamination was introduced by the primary beam. The base pressure in the ultrahigh vacuum chamber was 2.7 $\times 10^{-8} \mathrm{~Pa}$ and increased to $4 \times 10^{-7} \mathrm{~Pa}$ during sputtering. $\mathrm{A}$ quadrupole mass spectrometer revealed that argon was the niajor residual gas responsible for the pressure rise during sputtering.

\section{Cu Deposition and Calibration}

For the depth-of-origin experiments, $\mathrm{Cu}$ was deposited onto the $\mathrm{Ru}$ by evaporation. Extensive studies ${ }^{4,5.25-32}$ have shown that under appropriate conditions, $\mathrm{Cu}$ grows onto $\mathrm{Ru}(0001)$ in a layerby-layer srowth mode (Frank-van der Merwe) for at least two atomic layers. The first $\mathrm{Cu}$ layer is bound more strongly to the $\mathrm{Ru}(0001)$ surface than are subsequent $\mathrm{Cu}$ layers, allowing convenient calibration of the $\mathrm{Cu}$ coverage by thermal desorption. Marz-grade $\mathrm{Cu}$ wire was wrapped around a tungsten filament and the tungsten filament was mounted on outgassing loops. By controlling the voltage across the deposition filament, reproducible $\mathrm{Cu}$ evaporation rates can be achieved.4,5,29-31 The deposition filament was outgassed for several hours before use; Auger revealed no contaminants in the deposited $\mathrm{Cu}$ layer.

The calibration of the $\mathrm{Cu}$ coverage was carried out by combining thermal desorption and Auger spectrrscopies. Cu was slowly, and in a controlled manner, evaporated from the Ru surface. The target was positioned in front of the Auger spectrometer, and 
the differentiated peak-to-peak intensities of the $\mathrm{Cu} 920$ and $60 \mathrm{eV}$ and the $\mathrm{Ru} 274 \mathrm{eV}$ Auger features were recorded for decreasing $\mathrm{Cu}$ coverages. A $3 \mathrm{keV}, 5 \mu \mathrm{A}$ electron beam was used and the modulation voltage was $2 \mathrm{eV}$. This method allows the determination of the $\mathrm{Cu}$ coverage via differences in electron mean free paths (between the $\mathrm{Cu}$ and $\mathrm{Ru}$ Auger features) and differences in the binding energies (between the first and subsequent $\mathrm{Cu}$ overlayers) simultaneously. As expected for layer-by-layer growth, a plot of the Cu vs. the Ru Auger intensities (Fig. 1a) was linear within $\mathrm{Cu}$ overlayers and showed sharp breaks at the completion of one monolayer. ${ }^{4,25-28,33}$ The $\mathrm{Cu} / \mathrm{Ru}$ Auger intensity ratio decreased steadily with heating time until one $\mathrm{Cu}$ monolayer remained (Fig. 1b).

The crystal was held at a constant temperature $(\approx 1000 \mathrm{~K})$ for the data shown in Fig. 1b. When only one $\mathrm{Cu}$ layer remains, the rate of decrease of the $\mathrm{Cu} / \mathrm{Ru}$ Auger intensity ratio changed sharply, and the $\mathrm{Cu}$ desorption has almost stopped. This sharp change in the desorption rate of the $\mathrm{Cu}$ is caused by the larger binding energy of the $\mathrm{Cu}$ to the $\mathrm{Ru}(0001)$ surface over that of subsequent layers of $\mathrm{Cu}$ bound to $\mathrm{Cu}$. The data points in the boxes in Figs. la and $\mathrm{lb}$ correspond to the same data point, illustrating poignantly the presence of precisely one $\mathrm{Cu}$ overlayer.

Because of the high laser power densities required, the saturation of the ionization of the sputtered $\mathrm{Cu}$ and $\mathrm{Ru}$ atoms is not achieved. Laser power studies of the ionization efficiency for sputtered $\mathrm{Cu}$ and $\mathrm{Ru}$ atoms were carried out using SNMS in order. These experiments involved determining signal levels for $\mathrm{Cu}$ and $\mathrm{Ru}$ from pure targets as a function of laser power. The results of these studies were used in conjunction with the known sputtering yields ${ }^{34}$ of $\mathrm{Cu}$ and $\mathrm{Ru}$ to determine relative ionization efficiencies. The resulting sensitivity factors allowed conversion of raw $\mathrm{Cu}$ and $\mathrm{Ru}$ signal counts originating from the $\mathrm{Cu} / \mathrm{Ru}$ target to a sputtering yield ratio. 
The Primary Ion Dose Dependence of The Sputtering Yield

The $\mathrm{Ru}(0001)$ crystal was cleaned by repeatedly heating the crystal in oxygen followed by heating in vacuum as described earlier. Again, AES, SIMS, and SNMS were used to assure a clean surface.

In the ion dose dependence of the sputtering yield of $\mathrm{Ru}(0001)$ experiment, the SNMS signal from a sputtered portion of the surface was repeatedly compared with the signal from the undamaged or "virgin" portion of the surface. The "virgin" surface is that portion of the surface that has not been damaged by ion bombardment. During ion dosing, the $200 \mu \mathrm{m}$ diameter, 10-20 nA ion beam was rastered over a $1 \mathrm{~mm}^{2}$ area for a known amount of time. A Faraday cup was used to measure both the ion beam and rastered beam dimensions to determine the total ion dose to the sputtered area.

Each Ru sputtering yield measurement involved measuring the sputtering yield from both the ion-dosed and the unsputtered portions of the crystal. Typically, data was collected from two positions on the crystal face. The ion beam was first centered on one of these positions and the Ru sputtered flux was measured. The crystal was then translated 3-4 $\mathrm{mm}$ to the second position and sputtering data was again collected. This translation between the two target positions was repeated 4-5 times, thereby removing any effects caused by fluctuations in laser intensity or in the instrument transmission. One of the positions then received a carefully controlled ion dose. Following the ion dose, data was again repeatedly collected from the damaged and virgin areas of the crystal. By continuing this process of data collection and ion bombardment, primary ion fluences of $>10^{16} \mathrm{Ar}^{+} / \mathrm{cm}^{2}$ were accumulated in the ion-dosed portion of the target. 
To minimize the time that the crystal was exposed to the residual gases, a series of experiments was carried out using a $200 \mathrm{nA} \mathrm{Ar}^{+}$beam. In these experiments, the primary ion dose was not allowed to accumulate, rather, the crystal was bombarded continuously (for 3 minutes) until a fluence of $>10^{16} \mathrm{Ar}^{+} / \mathrm{cm}^{2}$ was attained. This data ascertained that the observed Ru sputtering yield following a primary ion fluence of $>10^{16} \mathrm{Ar}^{+} / \mathrm{cm}^{2}$ was identical regardless of whether the crystal was dosed over a long period of time or quickly.

Experiments were also carried out with the crystal tilted at $+10^{\circ}$ and $-10^{\circ}$ relative to the primary beam in order to observe any angular change in the ion dose dependence of the sputtering yield. For these experiments, the primary ion beam current was $200 \mathrm{nA}$ and the rastered beam size was $2 \mathrm{~mm}^{2}$.

\section{RESULTS AND DISCUSSION}

\section{The Depth of origin of Sputtered Atoms}

In Table 2, the $\mathrm{Cu} / \mathrm{Ru}$ sputtering yield ratios, $\mathrm{Y}_{\mathrm{Cu}} / \mathrm{Y}_{\mathrm{Ru}}$, are shown for various $\mathrm{Cu}$ overlayer coverages. The: ratio of the sputtering yields of bulk $\mathrm{Cu}$ and bulk Ru, $\mathrm{Y}_{\mathrm{BULK}}, \mathrm{Cu} / \mathrm{Y}_{\mathrm{BULK}, \mathrm{Ru}}$, is $1.67,34$ a value less than the experimentally determined ratios for any of the studied Cu coverages. This is indicative of a strong surface contribution to the sputtering yield. The table further shows that values of $\mathrm{Y}_{\mathrm{Cu}} / \mathrm{Y}_{\mathrm{Ru}}$ rapidly increase with increasing $\mathrm{Cu}$ coverage. By the time 2.5 layers of $\mathrm{Cu}$ have been deposited, only one $\mathrm{Ru}$ atom is sputtered for every $38 \mathrm{Cu}$ atoms.

If we simply assume that $\mathrm{Cu}$ and Ru sputter as if from bulk $\mathrm{Cu}$ and $\mathrm{Ru}$ respectively, and that the sputtering depth-of-origin distributions are simila- for bulk $\mathrm{Cu}$ and bulk $\mathrm{Ru}$, then, for a coverage of one $\mathrm{Cu}$ monolayer: 


$$
\frac{Y_{\mathrm{Cu}}}{\mathrm{Y}_{\mathrm{Ru}}}=\frac{\mathrm{X} \mathrm{Y}_{\mathrm{BULK}, \mathrm{Cu}}}{(1-\mathrm{X}) \mathrm{Y}_{\mathrm{BULK}, \mathrm{Ru}}}
$$

Substituting the bulk sputtering yields for $\mathrm{Cu}$ and $\mathrm{Ru}, 4.5$ and 2.7, respectively, $\mathrm{X}$, the fraction of the sputtered atoms originating from the first atomic layer, can be calculated. Since at a $\mathrm{Cu}$ coverage of one munolayer $\mathrm{Y}_{\mathrm{Cu}} / \mathrm{Y}_{\mathrm{Ru}}$ equals 3.1, $\mathrm{X}$ is (qual to 0.65 . Therefore, roughly two-thirds of the sputtered atoms originate in the first layer.

In Fig. 2, $\mathrm{Y}_{\mathrm{Cu}} / \mathrm{Y}_{\mathrm{Ru}}$ is plotted as a function of $\mathrm{Cu}$ coverage. The smooth curve is the calculated result of a model which associates a mean free path or attenuation length with sputtering. Assuming an exponential depth dependence of the depth of origin, the mean free path, $\lambda$, is the the depth giving rise to $(1-1 / \mathrm{e})$ or approximately $63 \%$ of the sputtered atoms.

$\frac{Y_{C u}}{Y_{R u}}=\frac{Y_{B U L K, C u}\left[X\left(1-e^{-(n+1) t / \lambda}\right)+(1-X)\left(1-e^{-n t / \lambda}\right)\right]}{Y_{B U L K, R u}\left[X e^{-(n+1) t / \lambda}+(1-X) e^{-n t / \lambda}\right]}$

Here, $\mathrm{n}$ is the number of completed $\mathrm{Cu}$ monolayers, $\mathrm{X}$ is the fractional monolayer $\mathrm{Cu}$ coverage of layer $(n+1)$, and $t$ is the thickness of a $\mathrm{Cu}$ monolayer. A best fit of this model to the data yields a value of $2.2 \AA$ or 0.9 lattice units for $\lambda$. The characteristic depth of origin of sputtered atoms, $\lambda$, is the depth giving rise to the majority of the sputtered atoms and is roughly equal to one atomic layer in full agreement with Eq. (1). The model shows good agreement with the data. This is not the first suggestion that the probability for atomic ejection by sputtering decreases exponen- 
tially with depth. Analytical theory yields an exponential depth dependence. ${ }^{10-13}$

These results suggest that two-thirds of the sputtered atoms originate in the first atomic layer. The first layer yield, however, is less than that typically calculated in computer simulations. The $\mathrm{Cu} / \mathrm{Ru}(0001)$ system is expected to show a deeper depth of origin than that of a clean. single-element metal for several reasons. A Cu adatom is less effective in blocking the Ru substrate than a Ru adatom because of its lower mass, smaller size, and lower binding energy. Computer calculations using the TRansport of Ions in Matter (TRIM) code ${ }^{15,16}$ confirm these assertions. For one layer of $\mathrm{Cu}$ on $\mathrm{Ru}$, TRIM calculations yield a $70 \%$ reduction in the $\mathrm{Ru}$ sputtering yield, while calculations on bulk Ru show that $80 \%$ of the sputtered $\mathrm{Ru}$ atoms originate in the first layer, or alternatively, that a single layer of $\mathrm{Ru}$ reduces the substrate Ru sputtering yield by $80 \% .^{4}$

The TRIM calculation of a $70 \%$ suppression of the $\mathrm{Ru}$ sputtering yield by a single $\mathrm{Cu}$ overlayer is in excellent agreement with the results of our data analysis, a suppression of $67 \%$. The shallow depth-of-origin estimates of most sputtering computer simulations and the corrected analytical sputtering theory are fully supported by these experimental results. Our results clearly indicate that atom ejection by ion bombardment is mostly a firstlayer phenomenon.

\section{The Ion Dose Dependence of the Sputtering Yield of Ru (0001)}

The sputtering yield of $\mathrm{Ru}(0001)$ was followed as a function of primary ion dose over the range of $10^{13}-10^{16} \mathrm{Ar}^{+} / \mathrm{cm}^{2}$; it was found to decrease steadily with increasing primary ion dose until a fluence of $2 \times 10^{15} \mathrm{Ar}^{+} / \mathrm{cm}^{2}$ was reached. At higher fluences no further change in the sputtering yield was observed. The results 
from four separate experiments are shown in Fig. 3a. Each data point is the ratio of two measurements, one on the ion-dosed portion of the Ru crystal and one on the undamaged or "virgin" portion of the crystal. The reduction in the sputtering yield saturates at $50 \%$ of the initial yield. Scatter in the data in Fig. 3a is primarily due to uncertainties in determination of the primary ion dose, inherent in measurements of the rastered ion beam spot size and ion current. The results from a single experiment, shown in Fig. $3 b$, illustrate the reduced scatter. The smooth curves are the results of a simple empirical model which is explained below.

Since the primary ion fluences used are so low $\left(10^{13}-10^{15}\right.$ $\mathrm{Ar}^{+} / \mathrm{cm}^{2}$ ), a fraction of the sputtered portion of the Ru crystal has not been damaged by a primary ion impact. Therefore, the Ru SNMS signal, IOBS, from the sputtered portion of the crystal can be partitioned into two distinct contributions. The first is signal arising from ion impacts of a virgin site, $\mathrm{I}_{\mathrm{O}}$, and the second is signal arising from previously kombarded sites, $I_{D A M}$. The relative contribution from each of these is dependent upon the primary ion fluence, $\mathrm{J}$ :

$$
\mathrm{I}_{\mathrm{OBS}}(U)=\mathrm{I}_{\mathrm{DAM}}(\mathrm{J})+\mathrm{I}_{\mathrm{d}}(\mathrm{J})
$$

Using Poisson statistics and defining a damage cross section, $\sigma$, for a single ion impact as the area responsible for the reduction in sputtering yield, then:

$$
\begin{aligned}
I_{D A M}= & \gamma Y_{D A M}\left(1-e^{(-\sigma J)}\right) \\
& \text { and } \\
I_{O}= & \gamma Y_{O} e^{(-\sigma J)}
\end{aligned}
$$


The detection efficiency for $\mathrm{Ru}$ of our instrument is $\gamma_{;} \mathrm{Y}_{\mathrm{O}}$ and $\mathrm{Y}_{\mathrm{DAM}}$ are the actual $\mathrm{Ru}$ sputtering yields from virgin and previously impacted sites, respectively. The fraction of the surface that has been struck at least one time is $\left[1-\mathrm{e}^{(-\sigma J)}\right]$, so the unr.isturbed fraction is $\mathrm{e}^{(-\sigma \mathrm{J})}$. At low primary ion fluences, very little of the probed area is perturbed so that the observed signal is dominated by the sputtering yield from virgin sites. As the ion dose, J, increases, the number of virgin sites is reduced and the signal from these areas of the crystal decreases accordingly. Once the ion fluence is large enough, no virgin surface remains and only the sputtering yield from the damaged surface contributes to the observed signal. Combining Eqs. 3-5 yields:

$$
\left(\frac{I_{O B S}(J)}{I_{O B S}(J=0)}\right)=\frac{Y_{D A M}}{Y_{O}}+e^{(-\sigma J)}\left(1-\frac{Y_{D A M}}{Y_{O}}\right) \text { • }
$$

The observed signal from the sputtered portion of the crystal is $I_{O B S}(J)$, while that of the unsputtered area is $I_{O B S}(J=0)$. The data was fit to the model allowing the damage cross section, $\sigma$, and the ratio of the damaged to undamaged sputtering yields, $\mathrm{Y}_{\mathrm{DAM}} / \mathrm{Y}_{\mathrm{O}}$, to be adjustable parameters. A best fit of the model to the experiment was obtained with damage cross section, $\sigma$, of $2.7 \pm 1.0 \times 10^{-15} \mathrm{~cm}^{2}$ and a sputtering ratio, $\mathrm{Y}_{\mathrm{DAM}} / \mathrm{Y}_{\mathrm{O}}=0.49 \pm 0.08$. This damage cross section contains $4.3 \pm 1.6$ surface $\mathrm{Ru}$ atoms for a surface atom density ${ }^{35}$ of $1.58 \times 10^{15}$ atoms $/ \mathrm{cm}^{2}$. As Fig. 3 shows, the agreement between the experimental results and the model is excellent.

The observed decrease in sputtering yield for such low primary ion doses was unanticipated and to the best of our knowledge has never before been observed. It is unlikely that gross topographical changes can be occurring at these low fluences. 
Furthermore, surface roughening generally leads to increased sputtering yields. $1,36,37$ Changes in sputtering yields following lowto-moderate ion bombardment have been observed previously, but in all cases the sputtering yield actually increases with ion dose. , $^{1,38-40}$ The increase in sputtering yields following ion bombardment have been attributed to the removal of surface contamination. As sputtering is a physical process and most atoms arise from the first atomic layer, it is to be expected that surface contaminants would block the substrate atoms from being ejected.

It is conceivable that a surface impurity could lead to an enhanced sputtering yield. If an adsorbed impurity significantly reduced the binding energy of the Ru atoms in the near surface region by forming strong chemical bonds, the sputtering yield of the Ru could increase. Sputter removal of the contaminant would then lead to a decrease in the Ru sputtering yield. Two different experiments were carried out to ascertain that the observed sputtering yield depression was not caused by imp'urities. The Ru sputtering yield experiment was carried out on a heavily carboncontaminated Ru surface. ${ }^{6}$ In these experiments, the Ru signal decreased only by $20-30 \%$ following ion bombardment. Assuming that the limiting, high-ion-dose sputtering yields are equal for both the clean and the carbon-contaminated Ru surfaces, these results indicated that the presence of the carbon reduced the initial, undamaged $\mathrm{Ru}$ sputtering yield.

A possible source of surface contamination is the residual gas in the UHV chamber. A series of experiments was carried out to minimize the data collection time, thereby reducing the possibility of adsorption of residual gases. In these experiments, the primary ion beam current was increased to $200 \mathrm{nA}$, reducing the time required to reach the saturated sputtering yield depression. Data was collected only from the undamaged crystal $(\mathrm{J}=0)$ and following heavy ion bombardment, $\mathrm{J}>10^{16} \mathrm{Ar}^{+} / \mathrm{cm}^{2}$. The clean 
crystal was quickly heated before data collection and ion dosing to remove any adsorbed gases. These experiments repeatedly showed a $50 \%$ reduction in the $\mathrm{Ru}$ sputtering yield following ion bombardment. Furthermore, annealing the crystal after ion bombardment returned the sputtering yield of the damaged surface to its original, undamaged level. These experiments confirmed that an impurity is not causing the observed ion dose dependence of the sputtering yield of $\mathrm{Ru}(0001)$.

The results show that moderate ion bombardment of a $\mathrm{Ru}(0001)$ surface causes the Ru sputtering yield to be reduced by a factor of two. This reduction in the sputtering yield is fully saturated following a primary ion fluence of only $2 \times 10^{15} \mathrm{Ar}^{+} / \mathrm{cm}^{2}$. The model results in a damage cross section of $2.7 \pm 1.0 \times 10^{-15} \mathrm{~cm}^{2}$. A cross sectional area this size contains roughly 3-6 Ru atoms, a number similar in magnitude to the sputtering yield, the number of atoms ejected per incident ion. Since the size of the collision cascade is greater than $4.5 \times 10^{-14} \mathrm{~cm}^{2}{ }^{6}$ it is clear that this experiment is probing an area considerably smaller than the area perturbed by a single ion impact.

The small size of the experimentally determined damage cross section suggests that surface vacancies, created by the removal of sputtered atoms, leads to the sputtering yield depression. Because most of the sputtered atoms originate in the topmost layer, the measured damage cross section may represent a lower limit for the sputtering cross section of the virgin $\mathrm{Ru}(0001)$ surface. While the mechanism of the ion dose dependence of the Ru sputtering yield is unclear, one possibility is that when a primary ion enters a surface vacancy, the collision cascade originates one layer deeper into the crystal. The primary ion's first collision is with a substrate atom in the second layer. Less energy is deposited into the surface atomic layer, reducing the likelihood 
that a surface atom gains enough energy to overcome the surface potential; the result is a reduced sputtering yield.

To determine the influence of the primary angle of incidence. experiments were carried out with the crystal rotated $\pm 10^{\circ}$ with respect to the primary ion beam. We observed the identical sputtering yield depression at these angles as at normal incidence. This suggests that the sputtering yield depression is not strongly coupled to the crystal structure but is dominated by topographic changes in the surface layer.

Experiments are currently being planned to determine the universality of this strong ion dose dependence of the sputtering yield. Low ion fluence experiments will be carried out on a $\mathrm{Cu}$ single crystal oriented along the (111) axis. Observation of the sputtering yield reduction following ion bombardment on a variety of targets would have a great impact on current sputtering models.

\section{CONCLUSION}

(i) Nonresonant laser ionization of sputtered neutrals has been shown to be a powerful method of studying fundamental sputtering phenomena. Minimal matrix effects and low surface damage allow the observation of the major sputtered species in a quantitative manner.

(ii) The $\mathrm{Cu} / \mathrm{Ru}(0001)$ sputtering depth-of-origin experiment reveals that the majority of sputtered particles originate in the topmost atomic layer. Calculated depth-of-origin estimates are fully supported by our measurements. These results indicate that ion-based surface techniques, SIMS and SNMS, are among the most surface sensitive analytical techniques. 
Page 20

(iii) The ion dose dependence of the sputtering yield of Ru(0001) has shown an unexpected two-fold decrease for relatively low fluences. The small size of the measured sputtering damage cross section suggests that the decrease in the Ru sputtering yield is due to a primary ion landing in a surface vacancy created by a previous ion impact.

\section{Acknowledgments}

This work was supported by the U. S. Department of Energy, BES Materials Sciences, under Contract No. W-31-109-ENG-38. 


\section{REFERENCES}

1. H. H. Anderson and H. L. Bay, in Sputtering by Particle Bombardment I: Physical Sputtering of Single-Element Solids, edited by R. Behrisch, Springer-Verlag, Eerlin, (1981), chapter 4.

2. A. Benninghoven, Surf. Sci., 53, 596(1975).

3. F. M. Kimock, J.P. Baxter, and N. Winograd, Nuclr. Instr. Meth. Phys. Res., 218, 287-292(1983).

4. J. W. Burnett, J. P. Biersack, D. M. Gruen, B. Jørgensen, A. R. Krauss, M. J. Pellin, E. L. Schweitzer, J. T. Yates, Jr., and C. E. Young, J. Vac. Sci. Technol., A6, 2064(1988).

5. B. Jørgensen, M. J. Pellin, C. E. Young, W. F. Calaway, E. L. Schweitzer, D. M. Gruen, J. W. Burnett, and J. T. Yates, Jr., to be published in the proceedings of the NATO Advanced Study Institute of Materials Modification by High-Fluence icn Beams, Viano do Castelo, Portugal, Aug. 24 - Sept. 4, 1987

6. J.W. Burnett, M.J. Pellin, W.F. Calaway, D.M. Gruen, and J.T. Yates, Jr., submitted.

7. M. J. Pellin, W. Husinski, W. F. Calaway, J. W. Burnett E. L. Schweitzer, C. E. Young, B. Jørgensen, and D. M. Gruen, J. Vac. Sci. Technol. B5, 1477(1987). 
8. C. H. Becker and K. T. Gillen, Appl. Phys. Lett. 45(10), 1063(1984).

9. C. H. Becker and K. T. Gillen, Anal. Chem. 56, 1671(1984).

10. P. Sigmund, Phys. Rev. 184, 383(1969); 187 768(1969).

11. G. Falcone and P. Sigmund, Appl. Phys. 25, 307(1981).

12. P. Sigmund, Sputtering by Particle Bombardment II, ed. by R. Behrisch, Springer-Verlag, Berlin, Heidelberg (1981).

13. P. Sigmund, et.al., Nuclr. Instr. Meth. Phys. Res. B, to be published Feb. 1989.

14. M. Vicanek, J.J. Jimenez-Rodriguez, and P. Sigmund, Nuclr. Instr. Meth. Phys. Res. B, to be published Feb. 1989.

15. J. P Biersack and W. Eckstein, Appl. Phys. A34, 73(1984).

16. J. P. Biersack, Nucl. Inst. Meth. B27, 21(1987).

17. M. T. Robinson, J. Appl. Phys. 54, 2650(1983).

18. M. Rosen, G. P. Mueller, and W. A. Fraser, Nucl. Instru. Meth. 209/2 10, 63(1983).

19. D. E. Harrison, Jr., Rad. Eff. 70, 1(1983).

20. D. E. Harrison, P. W. Kelly, B. J. Garrison, and N. Winograd, Surf. Sci. 76, 311 (1978).

21. M. F. Dumke, T. A. Tombrello, R. A. Weller, R. M. Housley, and E. H. Cirlin, Surf. Sci. 124, 407(1983). 
22. K.M. Hubbard, R.A. Weller, D.L. Weathers, and T.A. Tombrello, accepted, Nuclr. Instr. Meth. Phys. Res. B.

23. M. J. Pellin, C. E. Young, W. F. Calaway, and D. M. Gruen, Surf. Sci. 53, 596(1975).

24. M. J. Pellin, C. E. Young, W. F. Calaway, and D. M. Giuen, Nucl. Instrum. Methods B13, 653(1986).

25. K. Christmann, G. Ertl, and H. J. Shimizu, J. Catal. 61, $397(1980)$.

26. H. J. Shimizu, G. Ertl, and K. Christmann, J. Catal. 61, $412(1980)$.

27. J. C. Vickermann, K. Christmann and G. Ertl, Surf. Sci. 120, 1(1982).

28. J. C. Vickermann, K. Christmann, G. Ertl, P. Heimann, F. J. Himpsel, and D. E. Eastman, Surf. Sci. 134, 367(1983).

29. J. T. Yates, Jr., C. H. F. Peden and D. W. Goodman, J. Catal. 94, 576(1985).

30. J. E. Houston, C. H. F. Peden, D. S. Blair and D. W. Goodman, Surf. Sci. 167, 367(1986).

31. H. Tochihara, G. Rocker, R. M. Martin, H. Metiu, and J. T. Yates, Jr. , Surf. Sci. 203, 44(1988).

32. C. Park, E. Bauer, and H. Poppa, Surf. Sci. 187, 86(1987). 
33. L. C. Feldman and J. W. Mayer, Fundamentals of Surface and Thin Film Analysis, North-Holland, New York, 1986.

34. N. Matsunami, Y. Yamamura, Y. Itikawa, N. Itoh, and Y. Kazumata, Institute of Plasma Physics Report of Nagoya University, Japan, IPPJ-AM-14, Chikusa-Ku, Nagoya 464, Japan, (1980).

35. M. W. Roberts and C. S. McKee in Chemistry of the Metal-Gas Interface, Clarendon Press, Oxford, (1978) Chap. 2.

36. U. Littmark and W.O. Hofer, J. of Materials Science 13, 2577(1978).

37. J.L. Whitton, W.O. Hofer, U. Littmark, M. Braun, and B. Emmoth, Appl. Phys. Lett. 36, 531(1980).

38. Y. Matsuda, Y. Yamamura, Y. Ueda, K. Uchino, K. Muraoka, M. Maeda, and, M. Akazaki, Japanese Journal of Applied Physics 25, 8(1986).

39. H.L. Bay, B. Schweer, P. Bogen, and E. Hintz, J. Nucl. Material $111 / 112,732(1982)$.

40. R. Behrisch, J. Roth, J. Bohdansky, A.P. Martinelli, B. Schweer, D. Rüsbuldt, and E. Hintz, J. Nucl. Material 93/94, 645(1980). 
TABLE 1. VARIOUS ESTIMATES OF THE DEPTH OF ORIGIN

\begin{tabular}{|c|c|c|}
\hline SOURCE & \multicolumn{2}{|c|}{$\begin{array}{l}\text { SPUTTERED } \\
\text { FRACTION ARISING } \\
\text { FROM FIRST LAYER }\end{array}$} \\
\hline Analytical theory ${ }^{10-12}$ & $\begin{array}{l}\text { Characterisic depth-of-origin } \\
\text { For sputtering from Cu: } \\
\quad \approx 2.5 \AA \text {, } 1 \text { atomic layer }\end{array}$ & $>60 \%$ \\
\hline TRIM $^{15,16}$ & $\begin{array}{l}\text { Binary collision, } \\
\text { Monte Carlo computer simulation } \\
\text { Amorphous target }\end{array}$ & $>75 \%$ \\
\hline MARLOWE 17,18 & $\begin{array}{l}\text { Binary collision } \\
\text { Monte Carlo computer simulation } \\
\text { Single-crystal target }\end{array}$ & $>75 \%$ \\
\hline $\begin{array}{l}\text { Multiple } \\
\text { Interaction } \\
\text { Simulation } 19,20\end{array}$ & $\begin{array}{l}\text { Single-crystal } \\
\text { Multiple interaction } \\
\text { Sputtering simulation }\end{array}$ & $>85 \%$ \\
\hline $\begin{array}{l}\text { In-Ga liquid } \\
\text { eutectic } \\
1,22\end{array}$ & Sputtering experiment & $>85 \%$ \\
\hline
\end{tabular}


Table 2. The $\mathrm{Cu} / \mathrm{Ru}$ Sputtering Yield for Various $\mathrm{Cu}$ Coverages

Cu Coverage

(Monolayers)
$\mathrm{Cu} / \mathbf{R u}$ Sputtering

Yield Ratio, SCu/SRu
$0.69 \pm 0.06$
$2.1 \pm .4$
$1.0 \pm 0.1$
$3.1 \pm .6$
$1.1 \pm .11$
$3.0 \pm .6$
$1.20 \pm .12$
$3.6 \pm .7$
$1.40 \pm .14$
$4.2 \pm .8$
$2.5 \pm .5$
$38 \pm 8$ 


\section{FIGURE CAPTIONS}

Figure 1. Auger data for the caibration of the $\mathrm{Cu}$ coverage on Ru(0001). Signal intensities refer to the differentiated peak-topeak heights. The dashed lines are to aid the eye. (a) The $R u(274$ $\mathrm{eV})$ Auger signal level is plotted as a function of the $\mathrm{Cu}(60 \mathrm{eV})$ Auger signal intensities. A sharp change in the slope occurs at a $\mathrm{Cu}$ coverage of one layer. (b) The ratio of the $\mathrm{Cu}$ and $\mathrm{Ru}$ Auger signals is shown as a function of heating iime. During heating times greater than 0 , the crystal was held at a constant temperature $l \approx$ $1000 \mathrm{~K})$. Note that at one $\mathrm{Cu}$ layer, the decrease in the $\mathrm{Cu} / \mathrm{Ru}$ signal ratio becomes relatively flat. The data points inside tr:e square boxes in (a) and (b) are the same data point.

Figure 2. The $\mathrm{Cu} / \mathrm{Ru}$ sputtering yield ratios, $\mathrm{I}_{\mathrm{Cu}} / \mathrm{Y}_{\mathrm{Ru}}$, are plotted as a function of $\mathrm{Cu}$ coverage. The smooth curve is the plot of an exponential depth-of-origin sputtering model described in the text.

Figure 3. The ratio of the sputtering yield from the ion-damaged $\mathrm{Ru}(000 \mathrm{i})$ surface to the sputtering yield from an undamaged $\mathrm{Ru}(0001)$ surface is plotted as a function of primary ion ciose. Each data point represents the measurement of the $R_{1}$ sputtering yield from both the damaged and the undamaged regions of the crystal. Results from four separate experiments are shown in (a), while results from a single experiment are shown in (b). The solid line in (a) is the result of a least squares fit of all of the data to the model described in the text. The solid line in (b) is the result of a least squares fit of the data from a single experiment to the model. 


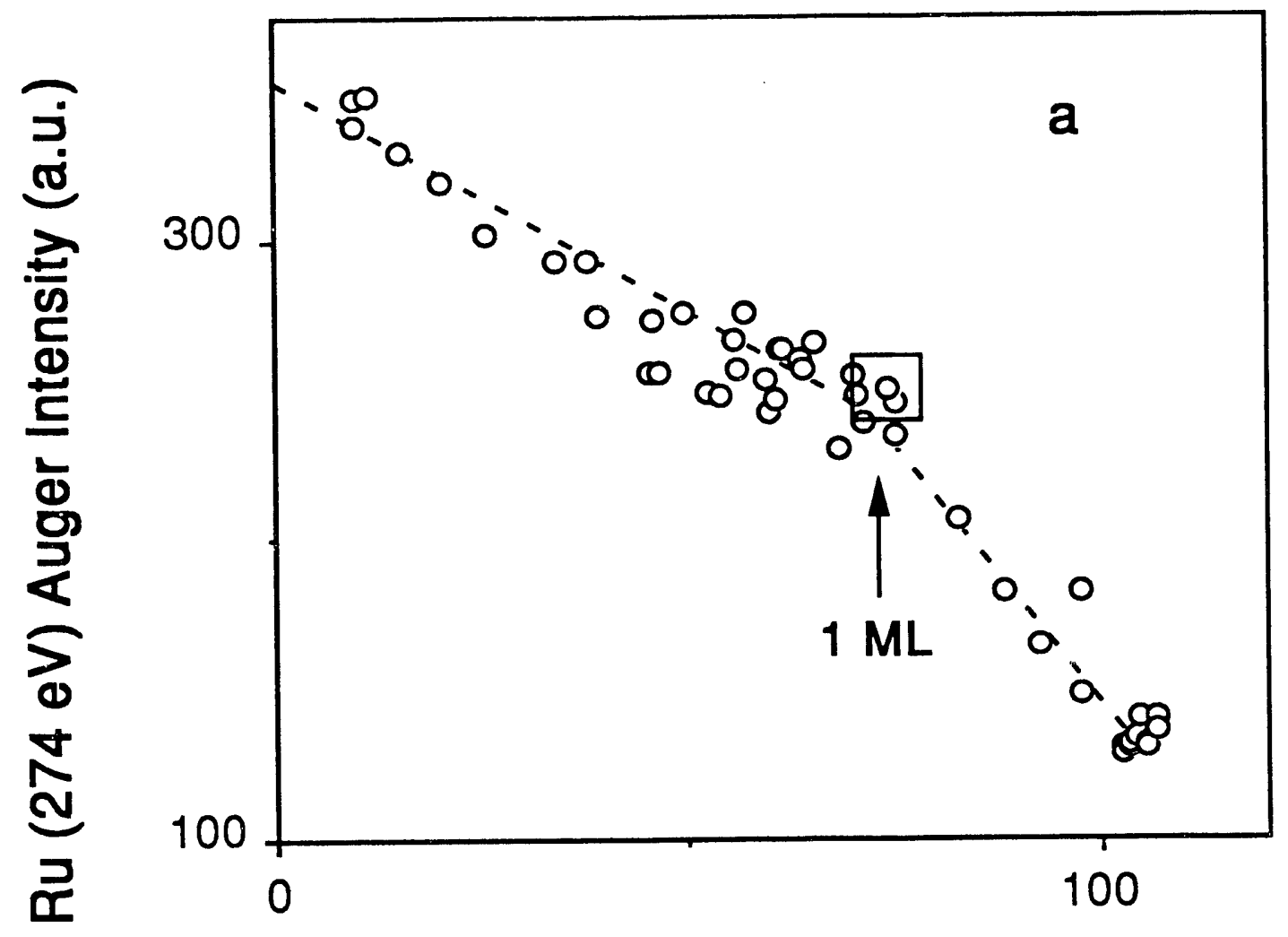

\section{$\mathrm{Cu}(60 \mathrm{eV})$ Auger Intensity (a.u.)}

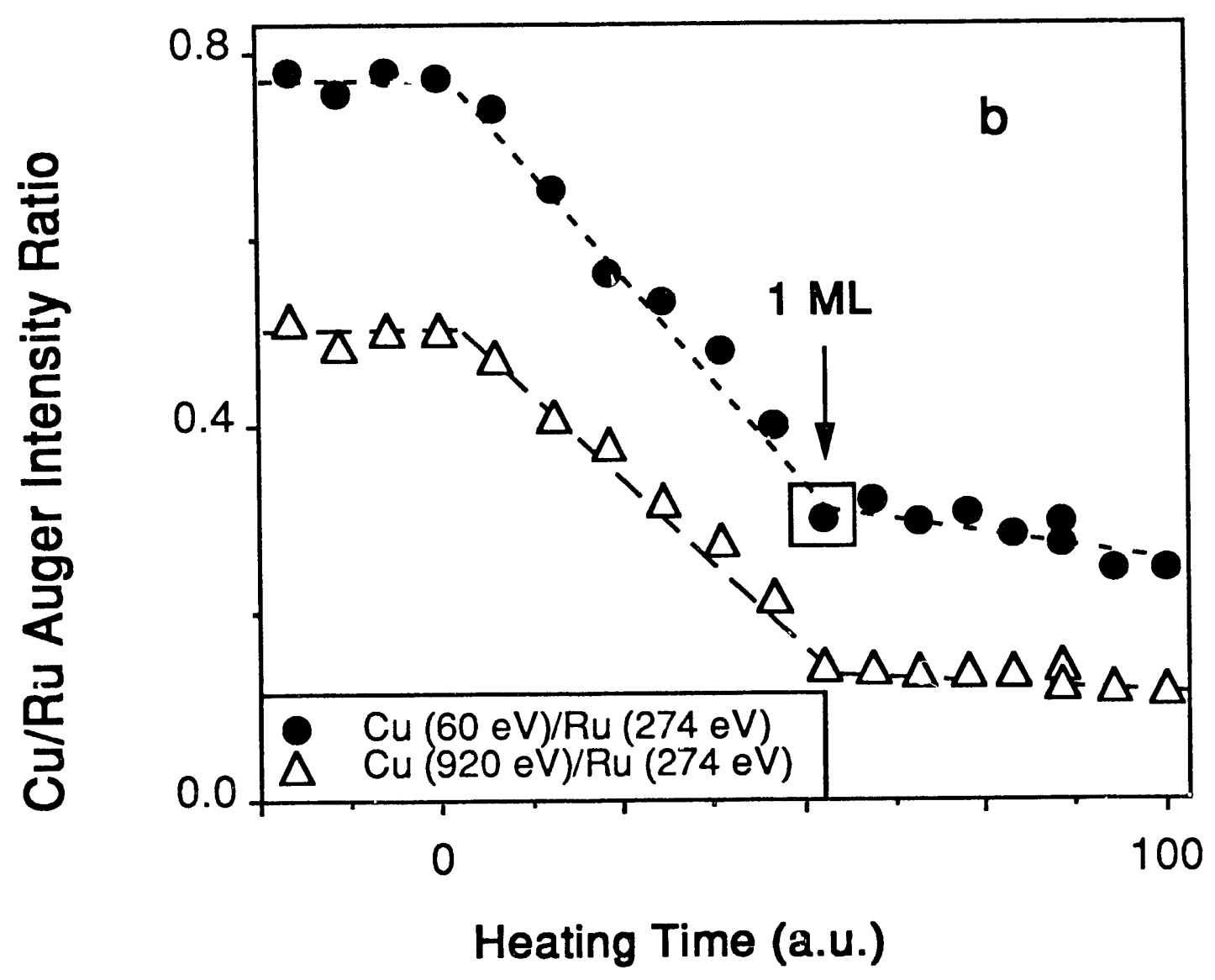



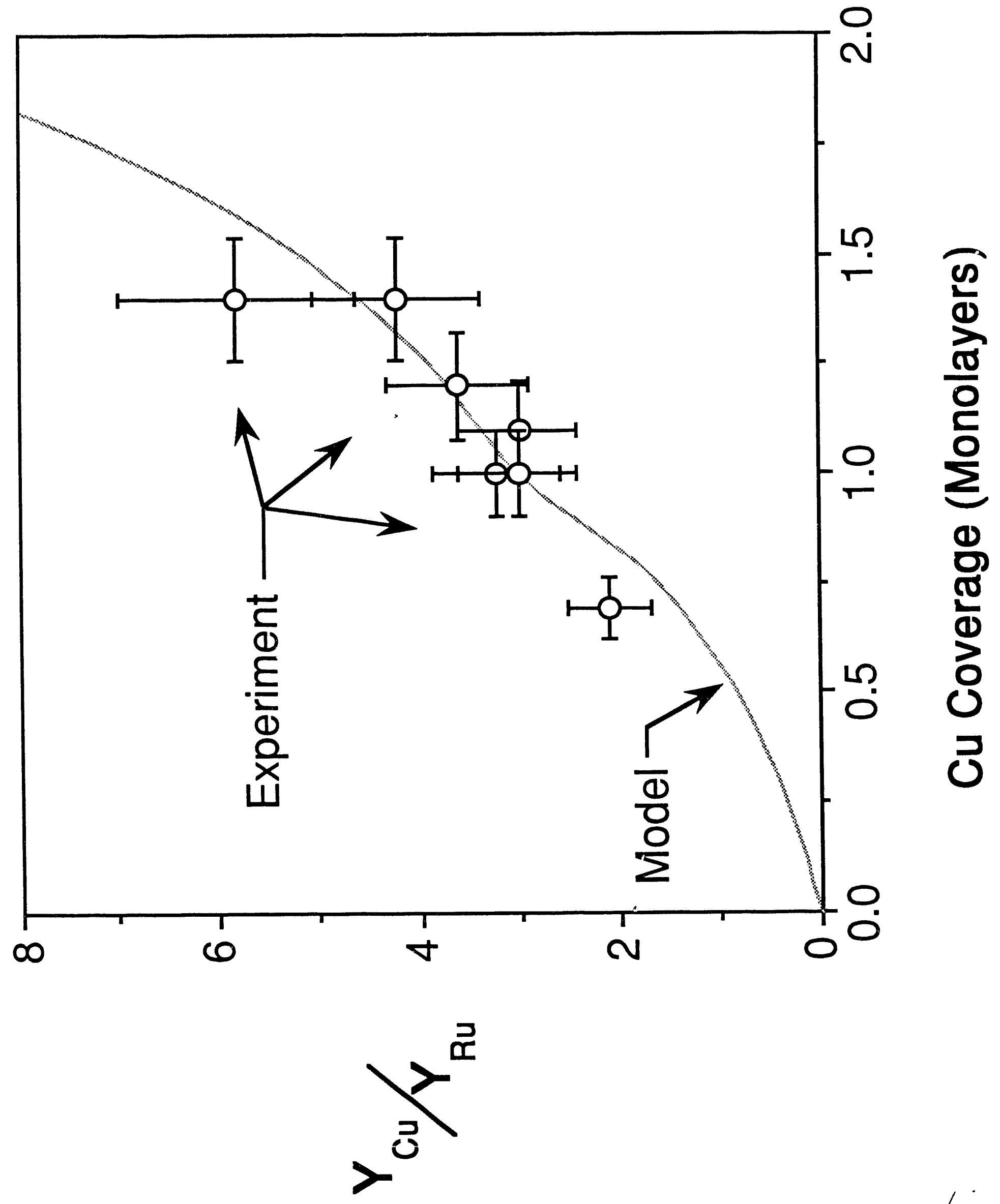

fig. 2 


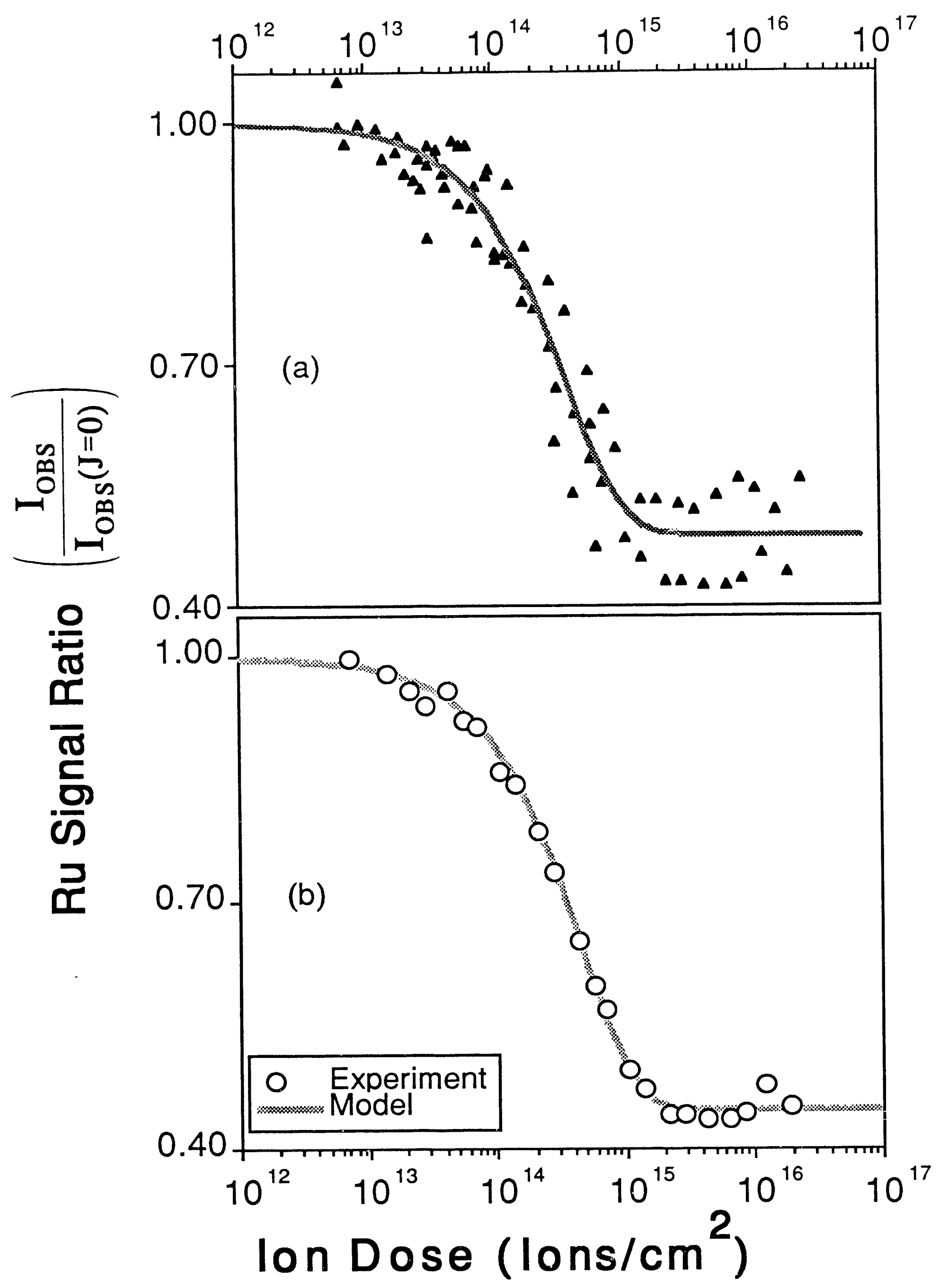

fig. 3 

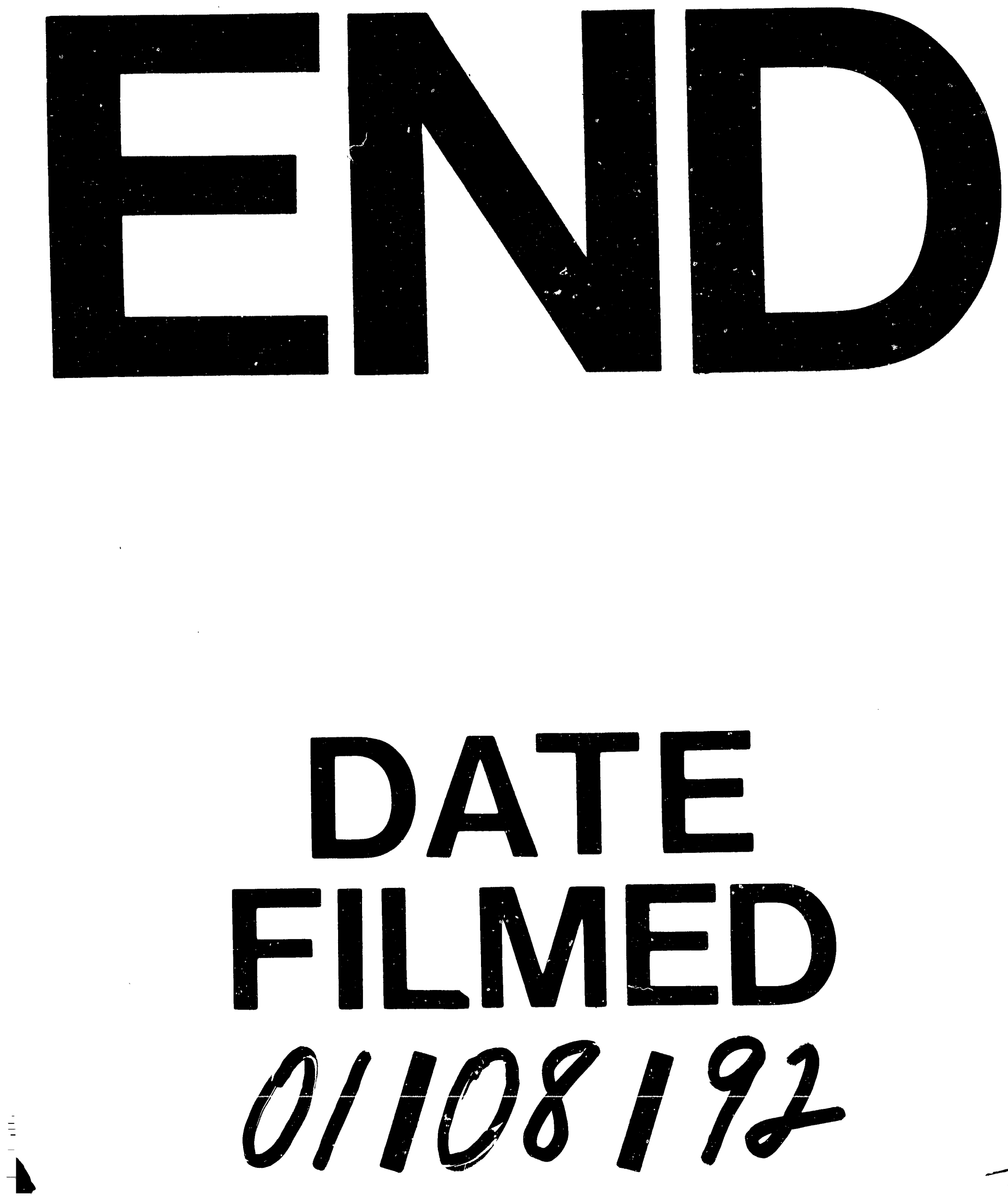


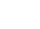

